\title{
The Influence of Type of Functional Groups on the Adsorption Selectivity of Ionic Imprinted Polymer iron
}

\author{
MUHAMMAD CHOLID DJUNAIDI*, RETNO ARIADI LUSIANA, \\ PARDOYO and META DIAN ARINI
}

\author{
Chemistry Department Faculty of Science and Mathematics Diponegoro University in \\ Semarang, Indonesia. \\ ${ }^{\star}$ Corresponding author E-mail: choliddjunaidi@live.undip.ac.id \\ http://dx.doi.org/10.13005/ojc/330635
}

(Received: August 01, 2017; Accepted: August 21, 2017)

\begin{abstract}
The selectivity of lonic Imprinted Polymer (IIP) Fe metal ion using functional polymers of eugenol derivatives was undertaken through the adsorption process. The forms of functional polymers were polyeugenol (PE), acetic polieugenoxy acid (PA) and poly tiophen-2-methyl-2eugenoxy acetate (PFMEA). The purposes of this research were to know the influence of functional groups on the functional polymer of eugenol derivatives to the adsorption selectivity of IIP involving imprint cavity. The method in this research is the lon Imprinted polymer (IIP) produced a metal ion imprint bound with the polymer, locked by Ethylene dimethacrylate (EDMA) then removed from the polymer to produce imprint selective to the ion imprinted. The adsorption selectivity of iron in PA was higher than PE and PFMEA. Analysis of surface area shows that IIP PA has larger surface area compared with NIP. The adsorption selectivity of $\mathrm{Fe}$ was higher on $\mathrm{Fe}-\mathrm{Cr}$ than $\mathrm{Fe}-\mathrm{Cd}$ and $\mathrm{Fe}-\mathrm{Pb}$.
\end{abstract}

Keywords: Polyeugenol, lonic imprinted polymer (IIP), Ethylene dimetachrylate, Selective adsorption.

\section{INTRODUCTION}

Chemiclas water polution is a problem all over the world. Heavy metals ion is one of the most dangerous because it is very toxic even in small quantities ${ }^{1}$. Although the iron metal is an essential mineral, existence of this metal in drinking water and ground water can cause a problem, such as discolourization, giving metal taste, the smell of muddiness and giving the spots on the laundry and plumbing. Iron oxide formed in tandon (reservoir) from the aeral oxidation of dissolved iron, evokes the growth of microorganisms in the water too. So, the world health organization, WHO (World Health Organization) makes a limitation iron $0,3 \mathrm{mg} / \mathrm{L}$ in drinking water ${ }^{2}$.

Development of cheap adsorbent which has high adsorption capacity is the main goal of much research. Ion imprinted polymer (IIP) is a method of printing metal into polymer, then it is released from the polymer matrix to produce imprint appropriate for ion imprinted. The advantages of IIP are high selectivity and easy prepared $^{3}$. 
Eugenol as the indonesia's natural ingredient is used for the separation or the metal ion. Eugenol can also be used as a basic material for synthesis of a compound because of the presence of its three functional groups, so it is potential for the functional monomer for the selective adsorption process like lonic Imprinted Polymer (IIP).

In this study the synthesis of IPP was undertaken using eugenol derivatives in the form of functional polymer variations; they are polyeugenol (PE), acetic polyeugenoxy acid (PA) and poly-thiohene 2-methyl-2-eugenoxy acetate (PFMEA) and cross linker agent EDMA (ethylene dimethacrylate) and AIBN initiator ((2.2', azobis (2metilpropionitril)) to test the selectivity adsorption for iron.

\section{EXPERIMENT}

The results of the synthesis of functional polymer of eugenol derivatives were used to synthesize both IIP and NIP in which in the synthesis of IIP, it was carried out contacting template in the form of $\mathrm{Fe}$ ions and then crosslinked with EDMA as a corsslink agent and AIBN as an initiator. The results obtained were then released of their $\mathrm{Fe}$ ions using acid, acid filtrate was added KSCN as complex agent to form complex compound which can be tested using UV-Vis spectrophotometer. Meanwhile, in the synthesis of NIP has the same procedure but the contacting with $\mathrm{Fe}$ ion in the beginning of the process was not undertaken. The final step was the adsorbent adsorption of functional polymer contacted with a binary metal mixture for 24 hours. Then, the filtrate of adsorption process was analyzed using atomic absorbtion spectrometer (AAS).

\section{Instruments}

Laboratory glassware, analytical balance, reflux apparatus, magetic stirrer, spatula, $\mathrm{pH}$ meter, filter paper, UV-Vis spectrophotometer (Shimadzu), Atomic Absorption spectroscopy (AAS) (Perkin Elmer), and Fourier Transform Infra Red (FTIR) (Nicolete Avatar 360), Scanning Electron Microscopy (SEM) (JSM-6510), Brunauer, Emmet dan Teller (BET)(Quantachrome).

\section{Materials}

Eugenol p. a, $\mathrm{BF}_{3}$ diethyl ether, Ethylene dimethacrylate (EDMA), AIBN (2.2 ', Azobis (2-methylpropionitrile), 2-thiophene methanol and $\mathrm{SOCl}_{2}$ that were purchased from sigma-aldrich, Anhydrous $\mathrm{Na}_{2} \mathrm{SO}_{4}, \mathrm{HCl}, \mathrm{NaHCO}_{3}, \mathrm{NaOH}, \mathrm{ClCH}_{2} \mathrm{COOH}$ Chloroform, Diethyl-ether, $\mathrm{KSCN}, \mathrm{Fe}\left(\mathrm{NO}_{3}\right)_{3}, \mathrm{Cr}\left(\mathrm{NO}_{3}\right)_{3}$ $\mathrm{Pb}\left(\mathrm{NO}_{3}\right)_{2}, \mathrm{Cd}\left(\mathrm{NO}_{3}\right)_{2}$ were purchased from Merck, Aqua deminaralized (Bratachem)

\section{Synthesis of materials, functional polymers and polyeugenol (PE). ${ }^{4}$}

$5,8 \mathrm{~g}$ eugenol $(0,035 \mathrm{~mol})$ was poured in the three-neck flask then added $1 \mathrm{~mL} \mathrm{BF}_{3}$ diethylether. The mixture was then stirred using stirrer for $4 \mathrm{~h}$ and in every $1 \mathrm{~h}, 0.25 \mathrm{~mL} \mathrm{BF}_{3}$ diethylether was added. The polymerization reaction occured during 12-16 $\mathrm{h}$ which was stopped by adding $1 \mathrm{~mL}$ of methanol. The gel formed was then dissolved in chloroform and then washed with Aqua Dest till neutral $\mathrm{pH}$ was achieved. The solution was then dried by adding anhydrous $\mathrm{Na}_{2} \mathrm{SO}_{4}$. After the solution was free of water/aquadest, the solution was evaporated at room temperature. The sediment left was dried and weighed. The product was analyzed using fourier transform infra-red spectroscopy.

\section{Synthesis of acetic polyeugenoxy acid (PA). ${ }^{5}$}

$5 \mathrm{~g}$ polyeugenol $(0,03 \mathrm{~mol})$ was added into the boiling flask with the size $100 \mathrm{~mL}$, after that, it was added $33 \% \mathrm{NaOH}$ solution $(0,825 \mathrm{~mol})$ as much as $17,5 \mathrm{~mL}$. Then, the mixture was stirred for about $30 \mathrm{~min}$. and added $12,5 \mathrm{~mL}$ of $50 \%$ chloroasetic acid solution $(0,529 \mathrm{~mol})$ drop by drop using pipette while stirring constantly. The mixture was heated in a water bath with temperature of $80-90^{\circ} \mathrm{C}$. The heating process was carried out for $2 \mathrm{~h}$, then cooled and acidified with $6 \mathrm{M} \mathrm{HCl}$ to obtain $\mathrm{pH} 1$. Subsequently it was extracted using $50 \mathrm{ml}$ diethylether 3 times. Ether extracts were combined and extracted with $30 \mathrm{ml}$ of $5 \%$ sodium bicarbonate $\mathrm{b} / \mathrm{v}(0,059 \mathrm{~mol}) 3$ times, then a layer of water was acidified with $6 \mathrm{M} \mathrm{HCl}$ to obtain $\mathrm{pH} 1$. Moreover, filtration, drying, and weighing to the product were conducted. The result obtained was analyzed using fourier transform infra-red spectroscopy. 
Synthesis of poly-thiophene 2-methyl-2-eugenoxy acetate (PFMEA)

$3 \mathrm{~g} \mathrm{PA}(0,0135 \mathrm{~mol})$ put in the bolling flask was added $3 \mathrm{ml}$ of thionyl chloride $(0,04 \mathrm{~mol})$, then refluxed for $240 \mathrm{~min} .\left(40^{\circ} \mathrm{C}\right)$ and after that allowed to cool. The next step was adding $2,5 \mathrm{ml}$ of 2 Thiophenemethanol $(0,027 \mathrm{~mol})$ drop by drop and then refluxing back for $240 \mathrm{~min}$. $\left(40^{\circ} \mathrm{C}\right)$. After getting cool, it was dissolved in chloroform and washed with aquadest, dried using anhydrous $\mathrm{Na}_{2} \mathrm{SO}_{4}$. Subsequently, filtration and evaporation of the solvent were undertaken. The results was then analyzed using fourier transform infra-red spectroscopy.

\section{Synthesis of IIP, NIP and Fe IIP}

$0.5 \mathrm{~g}$ polyeugenol $(0,003 \mathrm{~mol})$ was stirred with ion Fe (III) in certain concentration for $24 \mathrm{~h}$, Then, it was filtered using a filter paper and dried in the room temperature until dry. Polyeugenol-ion Fe (III) produced of about $0,222 \mathrm{~g}$ was then crosslinked with $0,4 \mathrm{~mL}$ (5 mol) EDMA as a cross linker agent, it was then mixed with $1,67 \mathrm{~mL}$ chloroform and added $0,48 \mathrm{ml}$ AIBN as an initiator. After that, the mixture was refluxed till the temperatures reached $110^{\circ} \mathrm{C}$. The result in the form of sediment was then dried. $0,2 \mathrm{~g}$ of polymer sediment produced was then treated with acid for $24 \mathrm{~h}$ to release $\mathrm{Fe}$ (III) ion and finally, ion Fe(III) IIP was generated.

The next procedure was the same as synthesis of $\mathrm{Fe}$-IIP procedure, the difference lay on the functional polymers used, namely, acetic polyeugenoxy acid and thiophen of poly-2-methyl2-eugenoxy acetate.

\section{Synthesis of NIP}

NIP was synthesized in the same way with IIP but without the binding of Fe (III) first. Characterization of IIP and NIP was carried out using fourier transform infra-red spectroscopy.

\section{Adsorption experiment}

$50 \mathrm{mg}$ adsorbent was contacted with the mixture of $10 \mathrm{~mL}$ ion $\mathrm{Fe}$ (III) (10 ppm) and $10 \mathrm{ppm}$ competitor ion for $24 \mathrm{~h}$ and stirred constantly. The mixture was filtered with a smooth filter paper.

\section{The selective adsorption test}

The selective adsorption test was undertaken on the competitive adsorption of binary aqueous solution consisting of $\mathrm{Fe}$ (III) / $\mathrm{Cd}$ (II), $\mathrm{Fe}$ (III) / $\mathrm{Cr}$ (III), $\mathrm{Fe}$ (III) / $\mathrm{Pb}$ (II) and then compared to NIP.

\section{Materials characterisation}

The concentration of $\mathrm{Fe}$ (III) and competitor metal ion in the filtrate of the adsorption experiment result was determined using Atomic Absorbtion Spectrometer (AAS). FTIR, BET and SEM were analysed for cahacterisation materials.

\section{RESULTS AND DISCUSSION}

\section{Syntesis of materials}

Synthesis Polyeugenol (PE), polyeugenoxy acetic acid (PA) were analised and discussed in others paper. ${ }^{4-10}$

\section{Synthesis of poly-thiophene 2- methyl 2- eugenoxy acetate}

Synthesis of poly-thiophene 2-methyl 2eugenoxy ecetate is a reversible esterification reaction with high yield so that thiophene methyl eugenoxy acetate should be produced in the form of chloric acid by the addition of thionyl chloride to obtain the yield more than $80 \%$. Then, it was added chloroform as a solvent to protect the ester formed from being hydrolyzed back. The result obtained was brownish-brown in the powder form with a distinctive odor and yield $93,17 \%$. Further it was analyzed using FTIR to identify the character of eugenol ester.

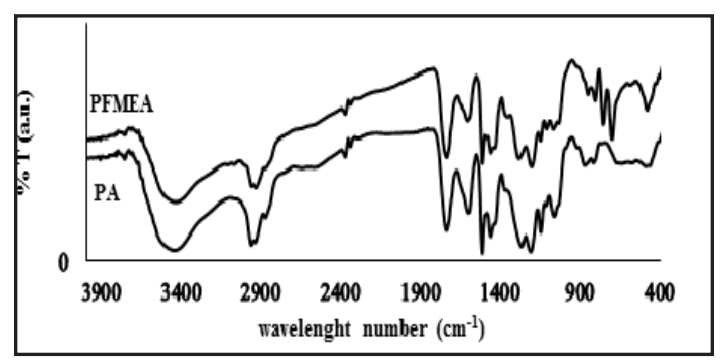

Fig. 1. PA comparison spectra with PFMEA

The FTIR spectra in figure 1 shows that compounds analyzed have $\mathrm{C}=\mathrm{C}$ bond indicated with the presence of absorption band at $1627 \mathrm{~cm}^{-1}$, $\mathrm{Csp}^{2}-\mathrm{H}$ with the absorption band at $2931 \mathrm{~cm}^{-1}, \mathrm{C}-\mathrm{C}$ with the absorption band at $1435 \mathrm{~cm}^{-1}$, and the absorption band at $1735 \mathrm{~cm}^{-1}$ and the loss of acid C-O absorption at $1149 \mathrm{~cm}^{-1}$ replaced with the appearence of ester C-O absorption at $1072 \mathrm{~cm}^{-1}$, it can be concluded that the poly-thiophene-2methyl-2-eugenoxy acetate was formed. 


\section{Synthesis of IIP}

In the synthesis of IIP, each functional polymer was contacted with 50 ppm Fe (III) ion $(\mathrm{pH} 3)$ and stirred for 24 hours. Then the result was filtered using filter paper and dried. Fe-functional plymer produced was cross-linked with EDMA crosslinking agent in chloroform and added AIBN as an initiator. The mixture was refluxed until the temperature reached $110^{\circ} \mathrm{C}$. Furthermore, the resin was acidified to realease $\mathrm{Fe}$ (III) for $24 \mathrm{~h}$ using $\mathrm{HCl}$ and checked everyday with UV-Vis spectrophotometry. In the present test, the filtrate from acidification process was added $\mathrm{KSCN}$ as a complexing agent, the colour of filtrate turned into red indicating the presence of iron released from the resin. The reaction is as follow. ${ }^{11}$

The test was performed until no longer red complex was formed, the colour of filtrate was clear when the addition of KSCN was undertaken, it means that there was no iron released. Acid compound of polyeugenoxy acetate is able to bind more Fe (III) ion templates than other functonal polymers, this was indicated by the high absorbance value in template release process using acid. The resin which has been discharged the template was then dried and can be used as an adsorbent to adsorb metals.

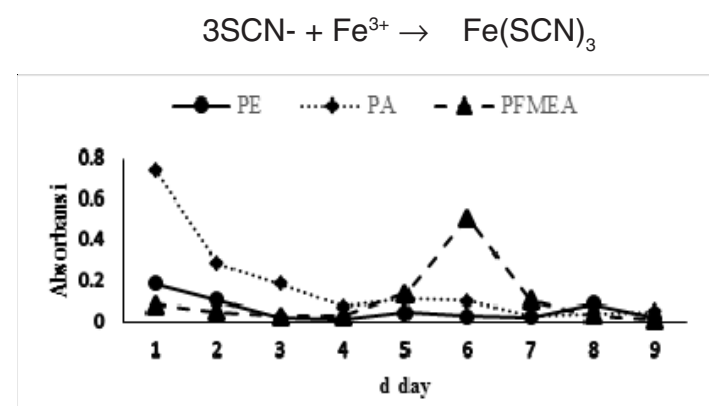

Fig.2. Graph release Fe template

\section{Materials characterisation.}

\section{Analysis of FTIR.}

In Fig.3 it appears that the -OH polieugenol spectrum decreases in intensity when attached to Fe-EDMA, this intensity then rises again after the $\mathrm{PE}-\mathrm{Fe}$-EDMA polymer is released Fe-containing iron ions to produce IIP. The IIP spectrum is sharper than NIP, it shows the role of -OH in IIP work. It also shows that there is a difference in Polyugenol emerging acid carbonyl spectrum after crosslinked with EDMA, this is because EDMA has an acidic carbonyl group that produces peak at wave number around $1700 \mathrm{~cm}^{-1}$.
In Fig.4, there is a difference in the carbonyl acid spectra of $1720 \mathrm{~cm}^{-1}$ on polieugenoxy acetate acid which becomes sharper after crosslink with EDMA. This is because EDMA also has an acid carbonyl group. In Fig.5 the PFMEA spectrum difference appears after crosslinks of carbonyl ester to shift close to the acid spectrum $\left(1700 \mathrm{~cm}^{-1}\right)$. This shift occurs because of the bonds / carbonyl interactions with the atoms of the EDMA crosslinker.

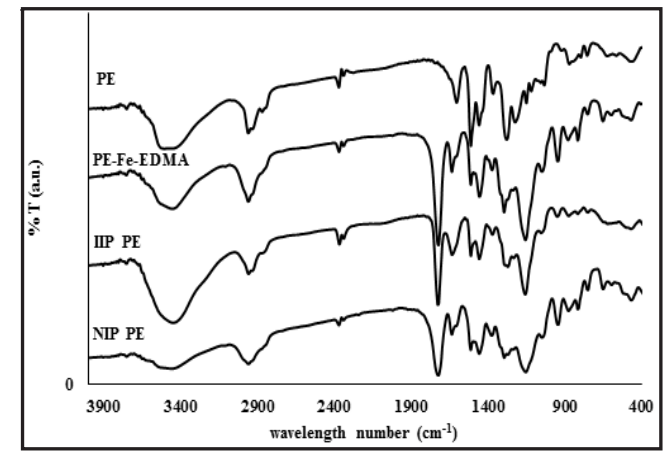

Fig.3. FTIR characterisation for IIP PE Synthesis

\section{Analysis of SEM}

One of functional polymers analysed using SEM was PA presented in Fig.6. Before the polymer PA changed to become IIP it has ununiform pores,

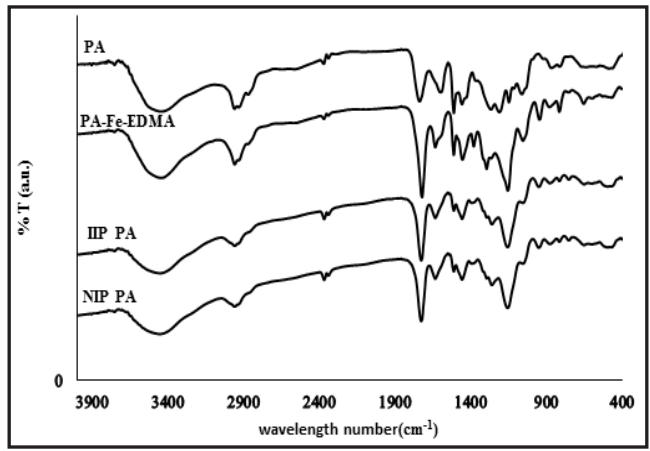

Fig.4. FTIR characterisation of IIP PA synthesis

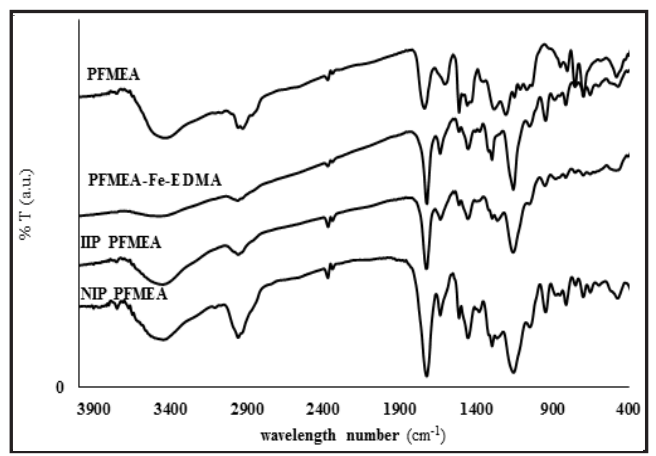

Fig.5. FTIR characterisation of IIP PFMEA synthesis 
but after the PA polymer became IIP the pores size was shown clearly become more uniform, regular and spread out. This could be because of the role of Fe bound and then released from the adsorbent, this result is in accordance with the research conducted by Djunaidi, et al.,(2016) .

\section{Analysis of surface area using BET method}

One of functional polymers analysed its surface area was PA performed using BET method. The result is as follows: IIP PA $=39.577 \mathrm{~m}^{2} / \mathrm{g}$, NIP $\mathrm{PA}=2.652 \mathrm{~m}^{2} / \mathrm{g}$, and NIP PA acid (immersion with $\mathrm{HCl})=5.353 \mathrm{~m}^{2} / \mathrm{g}$. It can be seen that the surface area of IIP PA decreased compared to NIP PA and NIP PA acid. Based on this result, it shows that IIP PA synthesis result underwent reorganization compared to NIP PA.

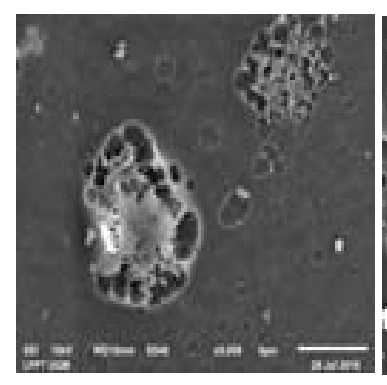

Before IIP

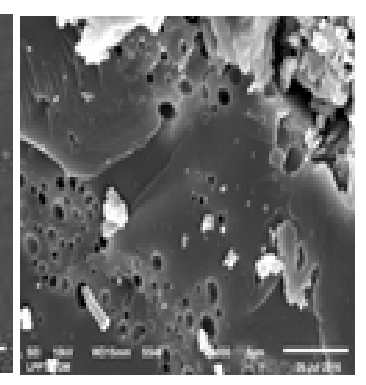

After IIP
Fig.6. SEM analysis on PA functional polymer

\section{Selectivity of Metallic ion adsorption}

The selectivity of Fe metal ion adsorption based on the variation of functional polymer used can be seen in Table.1. It is shown in Table.1 that the functional polymer of polieugenoxy acetic acid (PA) produced the greatest selectivity compared to other functional polymers. This could be since the acetic group has a chemical affinity for Fe (III) ions ${ }^{10}$.
The selectivity adsorption was calculated with formula \%adsorption $\mathrm{Fe}$ ion was divided by \%adsorption of competitor metal ion.

It is seen that the PE IIP sequence of similarity is similar to that of the study using the PEGDE croslinker ${ }^{8}$. This is due to the large number of $\mathrm{OH}$ groups in the polymer causing less affinity for $\mathrm{Cd}$ and its greater affinity for $\mathrm{Pb}^{8}$. Based on theory of $\mathrm{HSAB}, \mathrm{Fe}$ (III) and $\mathrm{Cr}$ (III) include in the group of hard acids which generally have a small atomic radius called hidrated atomic radius $\mathrm{Fe}$ (III) 0,66 $\AA$ and $\mathrm{Cr}$ (III) 0,62 Å. In the meantime, Cd(II) belongs to the soft acid group and $\mathrm{Pb}$ (II) enters in the medium acid group wich generally has a larger atomic radius, i.e, the hydrated atomic radius of $\mathrm{Cd}$ (II) and $\mathrm{Pb}$ (II) are respectively $0,96 \AA$ and $1,20 \AA^{12}$. The results showed that the adsorption selectivity of $\mathrm{Fe}$ on $\mathrm{Fe}-\mathrm{Cr}$ was higher than that of on $\mathrm{Fe}-\mathrm{Cd}$ and $\mathrm{Fe}-\mathrm{Pb}$, with the a selectivity sequence $\mathrm{Fe}-\mathrm{Cr}>$ $\mathrm{Fe}-\mathrm{Cd}>\mathrm{Fe}-\mathrm{Pb}$. The highest result of adsorption selectivity of $\mathrm{Fe}$ on $\mathrm{Fe}-\mathrm{Cr}$ indicated that the imprints formed were appropriate with the template, that is the adsorbent was suitable only for Fe metal. Although the $\mathrm{Fe}$ and $\mathrm{Cr}$ metals are in the same group with the similar properties but the imprints of the adsorbents are highly selective for Fe metals. The adsorption selectivity of $\mathrm{Fe}$ metal on Fe-Cd binary metal mixture was greater than that of on $\mathrm{Fe}-\mathrm{Pb}$, this is because $\mathrm{Fe}$ is categorized as a hard acid group with the hydrated atomic radius smaller than $\mathrm{Cd}$ categorized as soft acid groups and $\mathrm{Pb}$ in a medium acid group/borderline which has the hydrated atomic radius larger ${ }^{12}$. Cd metal has smaller hydrated atomic radius than that of $\mathrm{Pb}$ metal, this is the reason that the adsorption of $\mathrm{Fe}$ is greater on $\mathrm{Cd}$ than $\mathrm{Pb}$. The larger the hydrated atomic radius of the competitor metals it will prevent the Fe metal to enter the template, which further will cause the Fe metal selectivity becomes low.

Table. 1: The selectivity of Fe metal ion adsorption based on functional polymers

\begin{tabular}{lcccccc}
\hline Selektivity & IIP PE & NIP PE & IIP PA & NIP PA & $\begin{array}{c}\text { IIP } \\
\text { PFMEA }\end{array}$ & $\begin{array}{c}\text { NIP } \\
\text { PFMEA }\end{array}$ \\
\hline Fe-Cr & 4,03 & 6,10 & $\sim$ & 14,95 & 11,90 & 5,30 \\
$\mathrm{Fe}-\mathrm{Cd}$ & 11,51 & 2,02 & 82,92 & 19,00 & 11,25 & 17,31 \\
$\mathrm{Fe}-\mathrm{Pb}$ & 1,12 & 1,38 & 4,43 & 2,19 & 1,96 & 1,57 \\
\hline
\end{tabular}




\section{CONCLUSION}

The adsorption selectivity of $\mathrm{Fe}$ metal ion on plyeugenoxy acetic acid (PA) with the EDMA crosslinker was greater than that of the polythiphene 2-methyl-2-eugenoxy acetate (PFMEA) and polyeugenol (PE). The adsorption selectivity of $\mathrm{Fe}$ was greater on $\mathrm{Fe}-\mathrm{Cr}$ than on $\mathrm{Fe}-\mathrm{Cd}$ and $\mathrm{Fe}-\mathrm{Pb}$.

\section{ACKNOWLEDGMENTS.}

We would like to express sincere gratitude to Ministry of Riset and Technology Indonesia for Competitive Grant (Fundamental Grant 2017)

\section{REFERENCES}

1. Ghaee, A.; Niassar, M. S.; Barzin, J.; dan 7. Zarghan, A. App. Surf. Sci. 2012, 258 (19), 7732-7743.

2. Fan, H.; Sun, T. Korean J. Chem. Eng, 2012 29 (6): 798-803.

3. Harera; Rizal, L.; Sudiarti, T.; Wulandari, M. Al Kimiya. 2015, 2 (1), 30-39.

4. Djunaidi, M. C.; Jumina; Siswanta, D.; Ulbricht, M. Orient. J. Chem. 2016, 32 (1), 77-84.

5. Djunaidi, M.C.; Khabibi; Ulumuddin, I. IOP Conf. 2017 Ser: Mater. Sci. Eng. 172012032, 2017.

6. Djunaidi, M. C.; Jumina; Siswanta, D. ; Ulbricht, M., AIP Conference Proceedings. 1699, 060001, 2016.
Djunaidi, M. C.; Jumina; Siswanta, D.; Ulbricht, M. Asian J. Chem. 2015, 27(12), 4553-4562.

8. Djunaidi, M. C.; Jumina; Siswanta, D.; Ulbricht, M. Indones.J.Chem, 2015, 15(3), 305-314.

9. Djunaidi, M. C.; Siswanta, D.; Jumina. Orient J. Chem. 2015, 31(4), 2223-2229.

10. Djunaidi, M.C.; Lusiana, R.A.; Wibawa, P.J., Siswanta, D.; Jumina. Reaktor. 2010, 13(1), 16-23

11. Svehla, G. Vogels Text-Book Of Macro And Semimicro Qualitative Inorganic Analysis-5th Edition, 1979. Longman, London and New York.

12. Persson, Ingmar. Pure Appl. Chem., 2010. 82 (10): 1901-1917 